\title{
Environmental Pollution and Health Effects -Addressing Pollution (Air, Water and Noise) Challenges in Africa and Possible Solutions Towards Attaining Sustainable Green Environment
}

\author{
Wambebe Nathaniel M and Xiaoli Duan* \\ School of Energy and Environmental Engineering, University of Science and Technology Beijing, China
}

Submission: March 12, 2021; Published: April 06, 2021

*Corresponding author: Xiaoli Duan, Ph.D., Professor of School of Energy and Environmental Engineering, University of Science and Technology Beijing, 30 Xueyuan Road, Haidian District, Beijing 100083, China

Abstract

Pollution remains a major escalating challenge in Africa. Several deaths recorded every year across the continent are associated with this silent killer. The United Nations Environment's Global Environment Outlook-6's Regional Assessment for Africa states that African environment is deteriorating faster than previously thought and that government must act faster to reverse the worst trends. Nature is issuing red alerts as evidenced by the many environmental challenges being experienced in Africa including aggravating food shortages as well as various diseases. Some of the main causes of pollution include poor waste disposal systems, poor agricultural activities and industrial emissions. These have anthropogenic effects on the natural environment and also have serious impacts on humans and other forms of endemic life. There is therefore a link between environment and health as statistics point that environmental risks contribute a high percent of African's disease burden. Diarrhoea, respiratory infections and malaria account for a percent of known environmental health impacts in Africa. Environmental pollution could be air, water or land. They contribute to an increasingly unhealthy environment with the accompanying human health challenges. This paper recognizes that Africa's population is growing at a fast rate and yet not enough focus is being placed on the role environmental concerns play in ensuring the wellbeing of the expanding and dynamic continent. It states that the African environment is increasingly being polluted which has diverse negative health effects, as it constitutes a major threat to lives. The paper posits that there is need for urgent regulation and action to ensure that development takes environmental challenges and impacts into accounts. This will enthrone and ensure a clean and friendly environment that will promote health, wealth being and sustainable development.

Keywords: Pollution; Health; Africa; Green environment; Sustainability

\section{Introduction}

The rapid growth in human population has brought about several activities that are increasingly draining the natural resources and multiplying waste materials. On the other hand, human growth brings about advancement in science and technology, increasing urbanization and industrialization. Although these advancements have numerous benefits, they are major threats to the environment as they release lots of toxic materials into the environment. These unwanted materials gradually turn, not just into an African, but a global challenge as they pollute every aspect of the environment with the attendant health implications. Unfortunately, the main actors in environmental pollution are either nonchalant or show very little understanding of the impact of their activities on the present and future environment. The preservation of the human environment is embedded in the Sustainable Development Goals of the United Nations wherein nations are specifically called on to ensure a healthy environment. Various reports by the global body indicate that more efforts are needed towards the actualization of the objectives of sustainable development, including a healthy environment.

Environmental pollution is one of the serious challenges in Africa which has unimaginable effects on the health of humans, plants and animals. Studies and reports have shown that sustainable steps are to be taken to stop or reduce the degree and effects of contamination and to restore environmental health for all inhabitants. 
This paper examines the concept of environmental pollution in Africa and the health effects. It is divided into four parts. Part one is the introduction to the topic. Part two is an overview of what constitutes environmental pollution and the types of environmental pollution. Part three brings to the fore the health implications of the different types of pollution while part four gives a roadmap towards attaining a sustainable green environment. The concluding part contains the suggestions and conclusion.

This paper examines the concept of environmental pollution in Africa and the health effects. It is divided into four parts. Part one is the introduction to the to the topic. Part two is an overview of what constitutes environmental pollution and the types of environmental pollution. Part three brings to the fore the health implications of the different types of pollution while part four gives a roadmap towards attaining a sustainable green environment. The concluding part contains the suggestions and conclusion.

\section{The Concept of Environmental Pollution}

Man has generally been described as a specie with a lot of destructive tendencies. Much of the history of the western civilization has been characterized as exploitative, destructive and non-caring for the environment [1]. The environment is constantly stressed in various ways that it is presently posing a major threat to human health. Environmental pollution is the contamination of the environment in such a manner as to cause real or potential harm to human health or well-being; or to damage non-human nature without justification [1]. Environmental pollution refers to the undesirable change in the physical, chemical or biological characteristics of the air, land and water that may, or will harmfully affect human life or life of plants and animals, human living conditions and natural assets [2]. It is the unfavourable and undesirable alteration of an environment which renders it harmful to humans, plants and animals. It is environmental pollution when heavy toxic metals are built-up and accumulated in the air, water, and land such that it hampers the ability of the contaminated sites to support life.

Environmental pollution is a global issue as the world battles from one environmentally related challenge to the other. By a landmark report commissioned as part of the 2015 Paris Climate Agreement, it was found that rapid and unprecedented change is required to reduce global warming to a maximum of 1.5 degree Celsius; and that if global temperatures rise above that point, even by a fraction of a degree, future droughts, floods and heat waves will be seriously worsened [3]. Some 10,000 years ago, only few million people inhabited the earth (Our World in Data, 2019) and there were less anthropogenic activities. Today, there are population explosions, and the world is facing an environmental dilemma. With the world's current population of 7.8 billion and the projection of an increase of more than $25 \%$ by 2050 (World Population Data, 2020), the present Anthropocene epoch will witness billions of inhabitants who consume resources and consequently produce enormous wastes. Current population demands are depleting many of the earth's natural resources and ecological services. The impact of humans on the environment is related to population size, per capita consumption and the environmental damage caused by the technology used in producing what is consumed [4].

Sub-Sahara Africa suffers from many of the serious environmental problems including climate change, water pollution, nuclear waste, deforestation, poor sanitation, loss of biodiversity and industrial agriculture. The list of environmental challenges in Africa is endless.

The link between health and environmental protection was brought to the limelight at the first international conference on the human environment, held in Stockholm in 1972. At the conference, it was recognized that man is both the creature and moulder of his environment; that the natural and man-made aspects of man's environment, are essential to his well-being and to the enjoyment of basic human rights, even the right to life (United Nations, 1972). From that recognition came series of calls by the United Nations on states to recognize the right to a healthy environment in order to fight many environmental challenges, including pollution. In response to the call, many nations have adopted and ratified the legal obligations to respect, protect and fulfil the right to a healthy environment.

There are various kinds of environmental pollution, including air, water, noise, land or soil. Each of them has causes and impacts associated with it.

\section{a) Air pollution}

Air Pollution is the most popular type of environmental pollution faced by the world that threatens the environment and human health. This is because it is the most discussed form of pollution in modern political climate; and mostly due to discussions about greenhouse gasses that cause global warming [5]. The air we breathe has an exact chemical composition. Air pollution thus occurs when any sort of contaminant is introduced into the atmosphere such that it disrupts the chemical composition and renders the air unsafe. Typical examples include the release of particles into the air from burning fuels; and when there are dangerous gasses such as sulphur dioxide, carbon dioxide, nitrogen and chemical vapours in the air (Kourkouta Lambrini et al. 2018). Air pollution often looks like soot and contains millions of particles floating in the air. In the city of Port Harcourt, Nigeria, black soot covers the cloud on daily basis and this visibly stains human faces and skin, cars, floors and everywhere [6]. This is believed to be from illegal refining activities and the destruction of products from such illegal activities [6]. They can also take the form of greenhouse gasses such as carbon dioxide or Sulphur oxide which warm the planet through the greenhouse effect [7]. While all people living in a given area breathe from the same air, there are geographical differences in the extent of exposure to air pollution. 
Africa and Asia generally have a much higher level of air pollution compared to some other parts of the world [8]. This is due to the growing pressure for more travel and weak public transport system. There is however a different story in South Africa where there is relatively a sustainable transport system [9]. With the determination for sustainable improvement of the environment by reducing GHG, South Africa is committed to reducing GHG emissions to 5\% in the transport sector by 2022 . The country's transport sector had developed a Green Transport Strategy which among others, is aimed at promoting behavioural changes towards mobility alternatives [10].

Studies have shown that Niger remained at the top of air pollution in Africa from 2017 to 2019. The country's atmosphere has a concentration of up to $80.1 \mu \mathrm{g} / \mathrm{m}^{3}$ of fine particles, eight times above the WHO guideline level of $10 \mu \mathrm{g} / \mathrm{m}^{3}$ (State of Global Air, 2020). Nigeria is the second African country on the global chart with a concentration of $70.4 \mathrm{mg} / \mathrm{m}^{3}$. This represents an increase of 7.5 , from $62.9 \mu \mathrm{g} / \mathrm{m}^{3}$ in 2010 . The chief contributors to outdoor particulate matter include vehicle emission, gas flaring, unregulated burning of wastes, the use of solid fuel and bush burning.

\section{b) Water pollution}

Water Pollution is the contamination of water resources around the planet, ranging from rivers to ponds, lakes and any other source of water. It is the introduction of substances into the water in a quantity that its natural quality is altered as to impair its usefulness [11]. Natural or unpolluted water is tasteless, colourless and odourless. Thus, any water that tastes or smells or is cloudy is polluted. Water pollution is therefore characterised by the presence of physical, chemical or biological substances that change the quality of water and are capable of causing harm to living organisms [12]. 75\% of Africa's drinking water comes from groundwater and is often used with little or no purification. While the region's population doubled within the past years, there is no improvement on the access to quality water. Data have shown [13] that about half of the African countries will record water levels below 1,700 cubic meters per capita per year by 2025 . Africa has 63 international transboundary river basins covering about $64 \%$ of the region's land area. This accounts for $93 \%$ percent of the total surface water on the continent [13]. The abundance of water resources in the continent therefore, is not reflected in the quality of water. A study Albert Duncan [14] in the Ashanti region of Ghana revealed the presence of heavy metals in the Fena River due to illegal mining activities. Water contamination from mining results from the discharge of effluents containing toxic chemicals, such as cyanide and other organic chemicals used in the processing of mineral ores into sources of water supply. Cadmium, lead and iron were found to be the main pollutants of water sites in the area [14]. It is a daily experience in the Niger Delta region of Nigeria where oil activities have adversely affected water quality and the environment.
On the other hand, environmental noise pollution is the unwanted sound created by human activities that is considered harmful and detrimental to human health and quality of life [15]. Noise is sound that is out of place. Growth in population, industrial activities and increase in traffic are factors that aggravate noise pollution. The assessment of noise as pollution is a complex issue. This is because the characterisation of sound as noise and as an environmental pollution is subjective; it is an issue of perception and so depends on the individual experiencing the noise. But the points remain that noise is a type of sound and sounds are governed by set of rules. Most industries use big machines which produce large amount of noise. Furthermore, various equipment like compressors, generators, grinding mills also produce noise [16]. There is unreliable electricity supply in many African countries and this acts as clog in the wheels of Africa's development [17]. Globally, the population without access to energy is increasing with projection of a concentration of $90 \%$ being without access to electricity in 2040 living on the African continent (World Energy Outlook special report, 2019). In Nigeria for instance, the Power Holding Company of Nigeria is unable to maintain a steady supply of electricity for family, commercial and industrial use. Due to this, people and industries resort to generating sets for their various electricity needs. These generating sets produce discomforting noise to the users as well as the neighbourhood. This is in addition to poisonous gasses that they produce.

Soil pollution is a type of land pollution. It is the build-up in the soil of toxic compounds, materials or disease-causing agents which have adverse effects on plants and animal health [18]. Soil pollution occurs in various ways including from improper disposal of wastes, throwing of chemicals onto the soil in the form of pesticides, insecticides and fertilizers during agricultural practices, overgrazing and exploration of minerals. These lead to land degradation that affect soil quality and fertility. Most of the polluting metals are extremely persistent and readily accumulate to toxic level in the environment because they are mostly non-biodegradable and non-thermo degradable [19], Soil contamination has effects on the food we eat, the water we drink or the air we breathe (FAO, 2018). Poor agricultural practices like bush burning and irrigation with untreated wastewater contaminate the air and sources water which in turn affect humans.

A substance, condition, element or particle that contaminates the air, water or soil/land is called a pollutant. It could be primary or secondary [20]. Primary pollutants are emitted directly into the atmosphere while secondary pollutants are formed when primary pollutants react in the atmosphere. Emerging pollutants are closely associated with multiple man-made activities. These include activities from industries, transport, food production and general urbanization which are necessary for the development of modern society [21]. Pollutants can be naturally occurring substances that are in excess of the natural levels. 


\section{Health Effects of Environmental Pollution}

Environmental pollution is a serious global challenge that requires effective strategies for the preservation of environmental quality. Environmental pollution renders the environment unhealthy and harmful, with various adverse health effects. Studies have revealed a correlation between long term exposure to $\mathrm{PM}_{2.5}$ and premature mortality, ischemic heart disease, stroke, chronic obstructive pulmonary disease, tracheal and lung cancer [22]. Some of the most serious harmful effects are perinatal disorders, infant mortality, respiratory disorders, allergies, mental disorders and even death [23].

Environmental pollution is currently one of the biggest challenges facing the world. The World Health Organisation (WHO, 2016) had reported that air pollution kills about 3 million people annually, that it is affecting all regions of the world; and that $92 \%$ of the world's population are living in polluted regions that exceeds WHO's safety limits.

In Africa, it has been found that $28 \%$ of Africa's disease burden is as a result of environmental factors like contaminated water and air pollution; and that air pollution alone causes about 780,000 premature deaths per year [24]. A World Bank study 'The Cost of Air Pollution in Lagos' noted that under five mortality due to lower respiratory infection in Nigeria is the second highest in the world, after India. The black soot inhaled daily by residents of Port Harcourt, in the Niger Delta area of Nigeria constitutes a health challenge. Soot penetrates deep down in the lungs, imparting a wide range of serious health outcomes, including acute bronchitis and aggravated asthma among children, heart attacks, and strokes, as well as premature death (Okhumode H Yakubu, 2017). Further, the American Lung Association (2019) suggests that inhaling soot can potentially cause cancer as well as developmental and reproductive disorders. On the sustainable development report on Africa, UNECA (2018) noted that air quality in most African cities is poor and poses health risks, particularly for children. Children under five are the most affected group, accounting for about $60 \%$ of the total $\mathrm{PM}_{2.5}$-related deaths. It further reported that most countries in Africa do not meet the minimum air quality standards established by the World Health Organisation [25].

We breathe air to live and what we breathe has a direct effect on our health. The quality of air determines its effects on human health; and living in a pollution-free environment signifies a better quality of life. The health effects of air pollution could be long-term or short term. Air pollution is considered the biggest environmental risk to health and has continued to rise at an alarming rate, affecting lives and economies [26]. The World Health Organisation (2018) has described air pollution as an invisible killer as it may not always be visible but can be deadly. It has thus been described as a new epidemic demanding urgent attention [27]. Healthy environment is provided for under many of the UN's Sustainable Development Goals by either making a direct reference to the environment or being indirectly linked [28].
Air pollution affects the human health, the ecology as well as the wider ecosystem. The ecological effects include acidification of water and soil, crop damage, climate change, reduced plant growth, impaired photosynthesis, toxicity build up in food chain while impact on the ecosystem include reduction of plant biomass, altered nutrient cycling, and general change in ecosystems productivity. The health effects of air pollution include respiratory and cardiovascular diseases which are caused as a result of exposures to ozone and particulate matter; cancer, heart and lung diseases; impairment of neurological development and impairment of the human immune system [29]. Exposure to air pollution reduces life expectancy. A study has shown that Africa has the second mortality level in the world, after Asia (ScienceDaily, 2020). Air pollution is the world's greatest environmental risk to health as it causes premature death of about 6.5 million people across the world every year and still exposing a large number to unacceptable air pollution levels (WHO, 2016). The major sources of air pollution include fossil fuel emission from coal and heat; transport, industrial furnaces, agriculture and the unregulated burning of wastes. The use of generating sets in countries like Nigeria produce poisonous gasses that are injurious to living things. The effects of air pollution have been found to have a gender dimension as it affects women and girls more than men [30]. Unfortunately, most countries in Africa lack the infrastructure needed to map in detail the levels of pollutants most people are exposed to and how the pollutants affect human health.

The world is also facing a water quality challenge due to serious and increasing water pollution, both in developed and developing countries. In Africa, there is abundance of water resources, yet there is lack of quality water. This is a great challenge to health, food security, biodiversity and general livelihood. Severe pathogen and salinity pollution already affect one-third of river stretches in Africa, America and Asia [31]. The number of people coming into contact with unsafe waters ranges in hundreds of millions on these continents. It has also been found that there is a gender dimension to the effect of water pollution as women and children are the most vulnerable people [31]. This is because of their frequent usage of water from rivers and lakes for cleaning, cooking and drinking. The children on the other hand play in the surface waters and often have the task of collecting water for household use [31].

Diseases associated with polluted water include cholera, typhoid, ascariasis, diarrhoea, all of which are caused by ingestion of water polluted by protozoan, parasites, bacteria, viruses, faecal matters and from inadequate sanitation (WHO, 2020). Africa accounted for $94 \%$ of global malaria cases and deaths in 2019 with South Sudan, Nigeria, Democratic Republic of the Congo, Mozambique and Somalia in the list of Grade 3 emergencies, requiring substantial external and emergency support (WHO World Malaria Report, 2020). 
Humans and animals are exposed to heavy metal toxicity through the food web or through direct consumption of water containing metals. Effects of heavy metal toxicity on human health range from eye discomfort, nose and skin irritations to severe headache, stomach ache, diarrhoea, vomiting, dizziness to organ dysfunction and gastrointestinal distress among others (Monisha Jaishankar et al. 2014). Whereas some heavy metals are essential elements [32] and are required in certain amount in the body for various biochemical processes, others such as lead, arsenic, and mercury constitute serious threat to health [33]. Metals such as mercury and lead pass through the placenta of women and damage the brains of foetuses [18]. They can lead to learning difficulties, memory impairment, damage to the nervous system and behavioural issues such as aggressiveness and hyperactivity on infants and young children; metal taken at higher doses can cause irreversible brain damage [18]. A study was conducted [19] to determine the contamination level of heavy metals in vegetables and the soil as a result of irrigation. Using Flame Atomic Absorption Spectrophotometer, the result showed a concentration of 2.90$3.7 \mathrm{mg} / \mathrm{kg}, 2.20-3.68 \mathrm{mg} / \mathrm{kg}$ and $4.60-5.50 \mathrm{mg} / \mathrm{kg}$ of chromium $(\mathrm{Cr})$, cadmium $(\mathrm{Cd})$ and lead $(\mathrm{Pb})$ respectively. The concentration in the soil showed $22.37-66.30 \mathrm{mg} / \mathrm{kg}, \quad 27.93-45.33 \mathrm{mg} / \mathrm{kg}$ and $18.82-64.87 \mathrm{mg} / \mathrm{kg}$ for $\mathrm{Cr}, \mathrm{Cd}$ and $\mathrm{Pb}$, respectively. These concentrations were above the recommended limits of by WHO and FAO respectively [34]. Apart from the direct effects on human health through inhalation of polluted air or through occupational exposure at workplace, toxic metals can be concentrated in the soil and plants. This will affect the fertility and functionality of the soil and food quality [34]. Contaminated soil pollutes the groundwater. The pollutant is passed to the plants that are finally consumed by human beings. An investigation in the Northern part of Nigeria in 2010 after several deaths of both humans and ducks was traced to lead poisoning of the environment due to mining activities. Humans get infected as a result of consumption of fruits and vegetables that are contaminated [35].

Noise pollution is annoying and sometimes hazardous. It impacts millions of people on a daily basis, especially those in commercial cities in Africa. Noise is sound that is elevated to an unaccepted level and likely to harm or have effects on health. Such effects including hearing impairment, hypertension, interference with spoken communication, disturbance in sleep, annoyance, cardiovascular disturbance, disturbances in mental health, negative social behaviours, lack of concentration and general body irritation. Prolong exposure to noise pollution contributes to impairment in leaning among school children, changes in immune system, gestational hypertension and birth defects [36].

There is generally a growing threat to the environment and to human health in Africa and these are caused by increased generation of wastes and the complex problems of environmental contamination. In the Niger Delta area of Nigeria for example, there is a massive decline in the quality of the environment due to widespread contamination caused by exploration activities [37].
The pollution in the Niger Delta contaminates the agricultural land as well as the rivers. In one case, water was found to contain a known carcinogen at levels 900 times above WHO's guidelines (Amnesty International, 2011).

Research has identified poverty as the main cause and consequence of the man-made environmental pollution in the continent [38]. Poverty in this regard is viewed as a multidimensional issue that goes beyond the lack of income. Thus, the United Nations Development programme (UNDP, 2010) has included poverty to mean,

'the denial of opportunities and choices most basic to human development - to lead a long, healthy, creative life and to enjoy a decent standard of living, freedom, dignity, self-esteem and the respect of others.'

On the other hand, the global burden of poverty is established to be concentrated in Africa, with more than 150 million people living in extreme poverty as at first quarter of 2020 (World Data Lab, 2020). The reality is that roughly $40 \%$ of people in Africa live below US\$1.90 a day and sub-Sahara Africa accounts for about $60 \%$ of the global population living in poverty in 2020 [39]. With this level of poverty, there is an aggressive exploitation of available resources without consideration for future needs.

\section{Sustainable Green Environment}

Green environment relates to the act of showing deliberate concerns for environmental conservation and improved health of the environment. Being green is living one's life in a sustainable way and ensuring that one's activities as individuals or in a community reflect planetary resource limits. Man depends on the environment for practically everything. It is more of a moral obligation to protect the environment from pollution and other environmental degrading activities that threaten human life, animals and plants. Given the African's current state of environmental degradation that constitute risk to growth potential (Africa's Economic Outlook, 2020), Africans face a lot of dangers from the food they eat, the air they breathe, and the water they drink. This is an unimaginable self-imposed threat and sanitary risk that could lead to avoidable human tragedy if disregard for the environment and exploitation of natural resources become the norm [38]. It is therefore necessary to approach African's environmental problems head-on, in the most sustainable way. This involves a voluntary and committed partnership and collaborative efforts (Sustainable Development in Action, 2013). For the achievement of the SDGs and improvement of sustainable environmental health, all countries are stakeholders and key actors.

Sustainable development is a learning and acting process. It involves innovation which comes from a wide range of encounters between different bodies of knowledge and experience. Stakeholders are expected to keep exploring the concepts of sustainability and development. 
The tools or sound environmental alternatives for attaining green environment in Africa include:

\section{a) Education and Reorientation}

Education is a critical key driver in attaining a green environment in Africa (Joint AfDB-OECD Report, 2013). Improvement in education will enhance innovation, knowledge sharing and awareness about the myriads of environmental pollution and the public health implications. A reorientation on the responsible use of environmental resources, less dependence on fossil fuels and other depleting resources, saving the cost of waste disposal by recycling, reusing and reducing will ensure environmentally friendly lifestyles. There is already an increased recycling trend and the innovative approaches to reuse the collected waste in Africa [40]. This will change the trends and management of wastes in a world that generates 2.01 billion tonnes of municipal solid waste annually and likely to grow to 3.40 billion tonnes by year 2050 (World Bank, 2019). There are many wastes and recycling firms in Africa that engage in turning wastes to goods [41]. Recycling for Environmental Recovery is a Moroccan firm, supported by the World Bank that recycles plastic wastes into a range of secondary raw materials for the plastics industry for domestic use and for export [42]. With these, wastes would be turned to wealth and sustainable healthy environment would be achieved. Africa is already experiencing the ill effects of environmental deterioration on many fronts.

\section{b) Agriculture}

Agriculture has the potential of lifting the continent out of poverty and hunger as well as contribute to the overall GDP. There is a wide unexploited cropland in Africa. This important sector will grow significantly if there is support from governments and international bodies in form of finance, insurance, stable market, skills and business knowledge as well as the necessary technology required to appropriately harness and increase production beyond subsistence level. Improved Agriculture will promote food security in the continent, improve organic farming which in turn will minimize pollution, waste accumulation and ensure ecological sustainability as farmers will avoid the use of synthetics, pesticides and petrochemical fertilizers. The UNECA in its fifth report on Africa on Sustainable Development (2018) noted that the continent, excluding North Africa, wastes over 30 per cent of its approximately 230 million tons of annual food production (equivalent to more than US\$4 billion), due to large postharvest losses. With such report, agricultural productivity in the continent cannot translate into food security for most of the African countries. The UN organ further noted that there should be improvement in technology and creation of awareness to reduce resource-intensive production and limit food waste. This will also limit the Agricultural activities that are not environmentalfriendly.

\section{c) Use of green energy}

This means that homes are off the grid, saving the consumer money on electricity, ensuring constant power supply and avoiding noise pollution from power generating machines. According to the United Nations Economic Commission for Africa (2018), Ethiopia, Mali, Sierra-Leone and Uganda made the greatest strides in terms of decrease in energy intensive levels in Africa. The ECOWAS region ranked among the lowest in electricity access rates in the world, with about $42 \%$ of the total population and $8 \%$ of the rural residents having access to electricity (UN Chronicle, 2012). The inefficiency in energy efficiency and variations are attributed to lack of incentives, poor regulatory framework, inadequate infrastructure, poor designed building, lack of enforceable policy on energy efficient appliances and poor technologies [43]. The report has proposed a substantial increase in investment in the energy sector to meet the ever-growing energy demand and to deliver access to clean electricity and cooking facilities to the millions who currently do not have it [44].

\section{d) Green transport system}

The transport sector is one of the major contributors to GHG. Transportation system that uses electricity and solar system is trending in Africa. Example is the Kiira Motors Corporation, a solar-powered Vehicle Manufacturer in Uganda [45]. With that, there is zero emission and car battery is charged on the go. Such innovation should be supported as solar powered cars do not depend on the fluctuating oil price. They do not emit gas to the environment and so have no effects on natural resources.

On the other hand, countries should promote and support a transport system that is environmental-friendly. Example is in South Africa and Nigeria where there is network of Bus Rapid Transit which is aimed at reducing traffic congestion and deemphasising reliance on private transportation. While the system works better in South Africa, the case is different in Nigeria where people still prefer private transport system. This has continued to increase the number of vehicles on the road and generate vehicular emission which causes air pollution [46].

\section{Recommendation and Conclusion}

Water is greatly essential for life, just as air is. A healthy environment is necessary for a healthy life of both fauna and flora. Based on the strength of the research and knowledge regarding the adverse health effects of environmental pollution and the magnitude of their public health impacts, different kinds of intervention should be taken into account.

Identifying more environmentally sound development options is essential to meeting Africa's environmental challenges and to ensuring sustainable green environment. This can be achieved through improved education and orientation on the current tragic state of the African environment and the use of clean and 
renewable energy. The United Nations, through the Sustainable Development Goals Integration believes that action in one of the goals, will affect result in others. The world body also believes that the goals are integrated and that there is need for collaborative partnership in implementing the agenda for sustainability. There should be synergy among African countries in promoting and supporting green environment which is the best alternative for the continent. While the partnership for green environment among the countries is on, there should be an effective monitoring team to ensure that regulations are enforced in order to achieve results.

Environmental pollution can also be tackled from the human right perspective in which commission of same will amount to human rights violation. This is in line with the United Nations objectives as well as the regional treaties on the protection of the environment (The African Charter on Human and Peoples' Rights). An independent UN expert had said that the failure of governments across the world to ensure clear air constitutes a "violation of the rights to life, health and well-being, as well as the right to live in a healthy environment [47]."

The environmental pollution caused by human activities has brought and will continue to bring adverse consequences including food insecurity, threats to the physical environment and to human health which can lead to death. There is also a likelihood that the earth's resources are in danger of being exhausted.

Building a sustainable green environment in the face of the grave environmental abuse and consequent effects on health will not only restore and save the planet but will promote economic development and create jobs. It will take care of the environment for the present as well as the future generation.

\section{Authors' Contributions}

Author Wambebe put together the manuscript. All authors read and approved the final manuscript.

\section{References}

1. Jeffry PJ, Ruth WF, Aarne VP (1998) Environmental Pollution and Control. ( $4^{\text {th }}$ edn), Butterworths-Heinemann 1998 America, p. 2.

2. Shafi SM (2005) Environmental Pollution. Atlantic Publishers \& Distributors, New Delhi, India, p. 50

3. Climate Change threatens to Wreak Havoc on the Global Economy.

4. (2003) Speidel Joseph Environmental and Health Population, Consumption and Human Health in Lorey David ed Global Environmental Challenges of the Twenty-First Century Resources, Consumption and Sustainable Solutions Scholarly Resource Inc., USA.

5. The Types of Environmental Pollution: Understanding their Causes.

6. CNN Port Harcourt: Why is this Nigerian city covered in a strange black soot?

7. Alina B, Pollution Facts \& Types of Pollution.
8. (2016) World Health Organization Ambient Air Pollution: A Global Assessment of Exposure and Burden of Disease Report 14.

9. South Africa has created networks of Bus Rapid Transit, modern commuter trains improved paratransit (minibuses and taxis) and walking/cycling networks which aim to reduce traffic congestion. WHO Health and Sustainable Development.

10. SDG Knowledge Hub South Africa Launches Green Transport Strategy.

11. (2009) Srivastava Yogendra Environmental Pollution A P H Publishing Corporation New Delhi 23.

12. Study 7 Pollution: Types, Sources and Characteristics.

13. Odonkor AA, Water crisis in Africa: Scarcity amidst abundance.

14. Duncan AE (2020) The Dangerous Couple: Illegal Mining and Water Pollution-A Case Study in Fena River in the Ashanti Region of Ghana. Journal of Chemistry 2020(2378560).

15. Enda, Murphy, Eoin A (2014) King Environmental Noise Pollution Noise Mapping, Public Health, and Policy Elsevier Inc, USA 9.

16. Pantawane RN, Maske KV, Kawade NS (2017) Effects of Noise Pollution on Human Health. International Advanced Research Journal in Science, Engineering and Technology 4(3): 33-35.

17. IEA (2019) Africa Energy Outlook 2019, IEA, Paris.

18. Muhammad Aqeel, et al. (2014) Environmental Risk Assessment of Soil Contamination. In: Soriano MCH (Ed.), InTech Croatia 4.

19. Bahiru DB, Teju E, Kebede T (2019) Levels of Some Toxic Heavy Metals $(\mathrm{Cr}, \mathrm{Cd}$ and $\mathrm{Pb}$ ) In Selected Vegetables and Soil Around Eastern Industry Zone, Central Ethiopia Academic Journal of Agricultural Research 14(2): 92-101.

20. Bekir O, Surhid G (1997) Vehicular Air Pollution Experiences from Seven Latin American Urban Centers. World Bank Technical Paper 373: 14

21. Sonia S, Marcelo L (2018) Emerging Pollutants Some Strategies for the Quality Preservation of Our Environment. IntechOpen UK, p. 9.

22. Croitoru L, Akpokodje J, Chang JC, Kelly A (2020) The Cost of Air Pollution in Lagos. World Bank Study, p. 6

23. Roya K (2012) Environmental Pollution: Health Effects and Operational Implications for Pollutants Removal. Journal of Environmental and Public Health 2012(341637).

24. Katherine B (2019) Air Pollution Kills 780, 000 People in Africa Each Year. C \& En 97(17).

25. UNECA Africa (2018) Africa Sustainable Development Report Towards a Transformed and Resilient Continent, p.15

26. (2016) World Health Organization Ambient Air Pollution: A Global Assessment of Exposure and Burden of Disease Report 2016, p. 11.

27. World Health Organization Health and Sustainable Action on Air Pollution Approved at WHA 69.

28. The Sustainable Development Goals that directly address the environment include clean water and sanitation (Goal 6), Affordable and clean energy (Goal 7), sustainable cities and communities (Goal 11), Climate Action (Goal 13), Life on Land (Goal 15) while strictly speaking, other goals have a link with the environment.

29. UN Environment Air Pollution from Sources to Impacts.

30. Special Rapporteur on Human Rights and the Environment on the effects of air pollution. 
31. United Nations Environment Programme A Snapshot of the World's Water Quality: Towards a Global Assessment Nairobi, Kenya 2016, p. 39.

32. Some of the essential metals includes cobalt, copper, iron, manganese, vanadium and zinc. Other such as lead and mercury have devastating effects to the body. For example, exposure to lead has damaging effects on the kidney, brain, cause memory loss. Lead can affect every organ of the body. Agency for Toxic Substances and Disease Registry Case Studies in Environmental Medicine Lead Toxicity.

33. Inyinbor Adejumoke A, Adebesin Babatunde O, Oluyori Abimbola P, Adelani Akande Tabitha A, et al. (2018) Water Pollution: Effects, Prevention, and Climatic Impact, Water Challenges of an Urbanizing World, Matjaž Glavan, IntechOpen, DOI: 10.5772/intechopen.72018.

34. Bahiru DB (2020) Determination of Heavy Metals in Wastewater and Their Toxicological Implications Around Eastern Industrial Zone, Central Ethiopia. Journal of Environmental Chemistry and Ecotoxicology 12(2): 72-79.

35. Eugenio NR, McLaughlin M, Pennock D. Soil Pollution: A Hidden Reality' FAO Rome 5.

36. Reddy PB, Seema J (2012) Effects of Noise Pollution in Relation to Hypertension. Trends in Life Sciences 1(2): 30.

37. Nwozor A (2020) Depoliticizing environmental degradation: revisiting the UNEP environmental assessment of Ogoniland in Nigeria's Niger Delta region. GeoJournal 85: 883-900.

38. Kalemba M (2011) The Complexity of Environmental Protection in Sub-Saharan Africa and Reduction of Poverty Ethiopian Journal of Environmental Studies and Management 4(1): 17.

39. Institute for Security Studies What is the Future of Poverty in Africa?

40. Report Linker Africa Waste Management Market | Growth, Trends, and Forecast (2020 - 2025) Globe Newswire 2020.

41. Waste and Recycling Companies in Africa.

42. https://global-recycling.info/archives/2574

43. UNECA Africa 2018 Africa Sustainable Development Report Towards a Transformed and Resilient Continent, p.14.

44. UNECA Achieving Sustainable Development in Africa through Inclusive Green Growth Agriculture, Ecosystems, Energy, Industry and Trade being the Sustainable Development Report on Africa Fifth Edition 2.

45. http://www.kiiramotors.com/

46. WHO Health and Sustainable Development.

47. UN News With a premature death every five seconds, air pollution is violation of human rights, says UN expert.

\section{Your next submission with Juniper Publishers} will reach you the below assets

- Quality Editorial service

- Swift Peer Review

- Reprints availability

- E-prints Service

- Manuscript Podcast for convenient understanding

- Global attainment for your research

- Manuscript accessibility in different formats ( Pdf, E-pub, Full Text, Audio)

- Unceasing customer service

Track the below URL for one-step submission https://juniperpublishers.com/online-submission.php 